
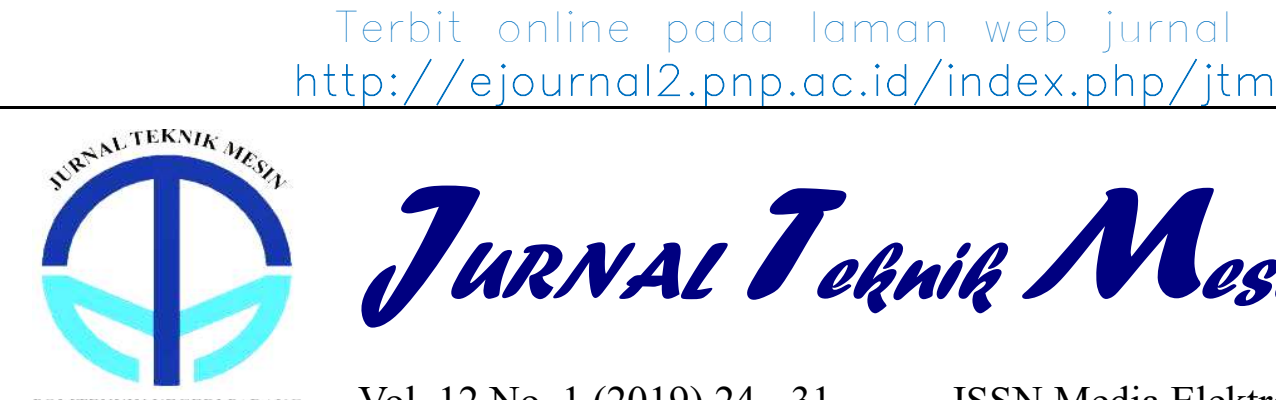

JuRnal Tognili Mosin

POLITEKNIK NEGERI PADANG

Vol. 12 No. 1 (2019) 24 - 31

ISSN Media Elektronik: 2655-5670

\title{
PEMBUATAN MESIN PENGIRIS BAWANG
}

Ricky Aldian Desrizal ${ }^{1}$, Rivanol Chadry ${ }^{2}$, Hendri Candra Mayana ${ }^{3}$,

${ }^{123}$ Jurusan Teknik Mesin, Politeknik Negeri Padang

fardinal@pnp.ac.id

\begin{abstract}
Abstrac
The main goal to be achieved is to be able to make an onion slicing machine so that it can answer the problem if the onion slicing is carried out in a larger capacity. The onion slicing machine is made to support the increase in the production of shallot slices, which are ready to be fried for the production of scallion onions in household industries. In a small scale, the work can be done manually with a knife or other simple cutting tool. Problems will arise if large quantities of sliced or cut production are available. In order to facilitate the community in processing shallots and learn about the problems, namely how to produce a shallot slicing machine with uniform slices results using different slope angles on the knife. the working principle of this machine is the Onion which has been peeled dry skin inserted into the funnel then the plate on the back of which has a knife, will rotate because it is driven by an electric motor. As a result of the rotation the onion will be sliced and the slice will fall down, and below it a container will be used as a cross section of the onion which has been finished sliced as a result
\end{abstract}

Keyword :Design, union slicing machine

\begin{abstract}
Abstrak
Tujuan yang hendak dicapai adalah dapat membuat mesin pengiris bawang sehingga dapat menjawab permasalahan jika pengirisan bawang dilakukan dalam kapasitas yang lebih besar. Mesin pengiris bawang ini dibuat untuk mendukung peningkatan hasil produksi irisan bawang merah, yang siap digoreng untuk produksi bawang goring skalaindustri rumah tangga. Dalam sekala kecil, pekerjaan tersebut dapat dilakukansecara manual dengan pisau atau alat pemotong sederhana lain. Permasalahan akan muncul jika produksi yang akan diiris atau dipotong tersedia dalam jumlah banyak. Agar memudahkan masyarakat dalam pengolahan bawang merah dan mempelajari masalah yang ada, yaitu bagaimana menghasilkan mesin pengiris bawang merah dengan hasil irisan yang seragam dengan menggunakan perbedaan sudut kemiringan pada pisau. prinsip kerja dari mesin ini adalah Bawang yang sudah dikupas kulit keringnya dimasukkan kedalam corong kemudian piringan yang dipunggungnya terdapat pisau, akan berputar karena digerakkan oleh motor listrik. Akibat putaran tersebut bawang akan teriris dan irisan tersebut akan jatuh kebawah, dan dibawahnya digunakan wadah sebagai penampang bawang yang sudah selesai diiris sebagai hasilnya
\end{abstract}

Kata Kunci : Perancangan, mesin pengiris bawang

\section{Pendahuluan}

Dengan bertambah luasnya panen bawang merah di Sumatra Barat dari tahun ketahun, membuat hasil produksi bawang merah juga meningkat. Bawang merah merupakan kebutuhan pokok dalam pemasakan terutama di bidang kulineri. Bawang merah sebagai bahan baku penambah, bahkan penikmat rasa dalam setiap masakan. Maka dari itu produksi dan konsumsi bawang merah di Sumatra Barat cukup tinggi sehingga diperlukan cara penanganan dan pengolahan dari bawang merah tersebut. Mesin pengiris bawang ini diharapkan mendukung peningkatan hasil produksi irisan bawang merah, yang siap digoreng. Dalam sekala kecil, pekerjaan tersebut dapat dilakukan secara manual dengan pisau atau alat pemotong sederhana lain. Permasalahan akan muncul jika produksi yang akan diiris atau dipotong tersedia dalam jumlah banyak. Menurut Koswara dalam 
pengolahan hasil pertanian banyak permesinan yang digunakan, diantaranya adalah mesin pengiris bawang yang digunakan sebagai teknologi yang memudahkan dalam penanganan dan pengolahan bawang. Mesin pengiris bawang merah ini diharapkan mendukung peningkatan hasil produksi irisan bawang merah, yang siap olah/digoreng [1]

Agar memudahkan masyarakat dalampengolahan bawang merah, penulis menawarkan "Mesin Pengiris Bawang". Setelah mengamati dan mempelajari lebih lanjut dari latar belakang masalah yang ada, yaitu bagaimana menghasilkan mesin pengiris bawang merah dengan hasil irisan yang seragam dengan menggunakan perbedaan sudut kemiringan pada pisau. Menurut Widiantara yang menyebutkan sudut kemiringan pisau $4^{\circ}$ adalah sudut yang paling baik yang menghasilkan irisan bawang yang seragam dengan ketebalan $1 \mathrm{~mm}$ [2].

Ada banyak faktor yang mempengaruhi kualitas pengirisan diantaranya kemiringan pisau, kecepatan motor dan kapasitas pengirisan menurur Rahmat S pengaruh lain dari pisau pengiris adalah pada kapasitas pengirisan, walaupun putaran pisau dijaga tetap pada putaran yang diinginkan tidak menghancurkan irisan bawang [3]. Untuk pembuatan mesin juga harus diperhatikan material dipilih berdasarkan fungsinya di bagian mesin menurut Anonim bahan yang digunakan harus sesuai dengan fungsinya, pada penentuan bahan yang akan digunakan harus mengetahui untuk apa bahan itu digunakan [4]

Adapun prinsip kerja dari mesin ini adalah sebagai berikut : Bawang yang sudah dikupas kulit keringnya dimasukkan kedalam corong kemudian piringan yang dipunggungnya terdapat piasu, akan berputar karena digerakkan oleh motor listrik. Akibat putaran tersebut bawang akan teriris dan irisan tersebut akan jatuh kebawah, dan dibawahnya digunakan wadah sebagai penampang bawang yang sudah selesai diiris sebagai hasilnya.

Tujuan yang hendak dicapai adalah dapat membuat mesin pengiris bawang sehingga dapat menjawab permasalahan jika pengirisan bawang dilakukan dalam kapasitas yang lebih besar dan dapat menentukan anggaran biaya pembuatan mesin.

\section{Metode Penelitian}

Pembuatan mesin pengiris bawang dilaksanakan mulai tanggal 5 Juni 2017. Tempat pelaksanaan dan kegiatan ini dilaksanakan di rumah dan workshop perbaikan perwatan Politeknik Negeri Padang.

\section{Diagram Aliran Pelaksanaan Pembuatan}

Adapun metode yang digunakan dalam pembuatan alat (mesin pengiris bawang) yaitu dapat dilihat pada Gambar 1:

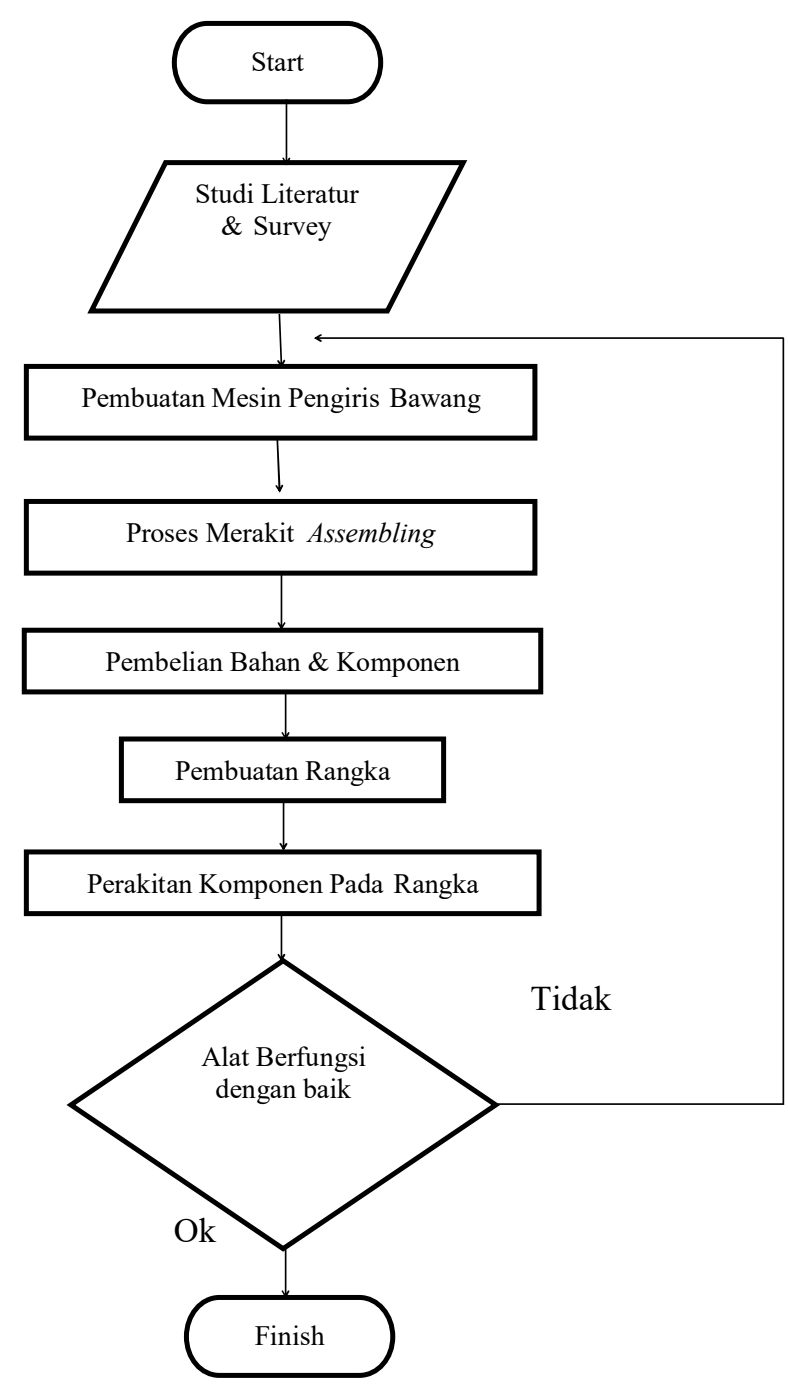

Gambar 1. Diagram Alir Metode Pembuatan

\section{Hasil dan Pembahasan}

Spesifikasi dari mesin ini adalah sebagai berikut: 1). Motor Listrik
a. Daya Motor
: $1 \mathrm{HP}$
b. Putaran Motor : $1400 \mathrm{rpm}$

2). Putaran Pisau : 466 rpm

3). Mata pisau
a). Panajang
: $100 \mathrm{~mm}$
b). Lebar
: $40 \mathrm{~mm}$
c). Tebal
: $2 \mathrm{~mm}$

4). Dudukan Pisau
a). Diameter dalam : $22 \mathrm{~mm}$
b). Diameter luar : $315 \mathrm{~mm}$
c). Tebal $\quad: 10 \mathrm{~mm}$

5). Tadah Penampung
a). Tinggi
: $150 \mathrm{~mm}$
b) Lebar
: $100 \mathrm{~mm}$

6). Rangka 

a). Panjang
: $600 \mathrm{~mm}$
b). Lebar
: $400 \mathrm{~mm}$
c). Tinggi
: $570 \mathrm{~mm}$

7). Dimensi Keseluruhan
a). Panjang
$: 1100 \mathrm{~mm}$
b). Lebar
: $500 \mathrm{~mm}$
c). Tinggi
: $920 \mathrm{~mm}$

\section{Komponen Mesin Pengiris Bawang}

Alat yang penulis buat memiliki beberapa komponen yang mendukung dan memiliki fungsi penting dalam proses kerja pada Mesin Pengiris Bawang yang penulis buat. Penulis menjelaskan satu persatu komponen yang digunakan pada Mesin Pengiris Bawang, dapat dilihat pada Gambar 1.

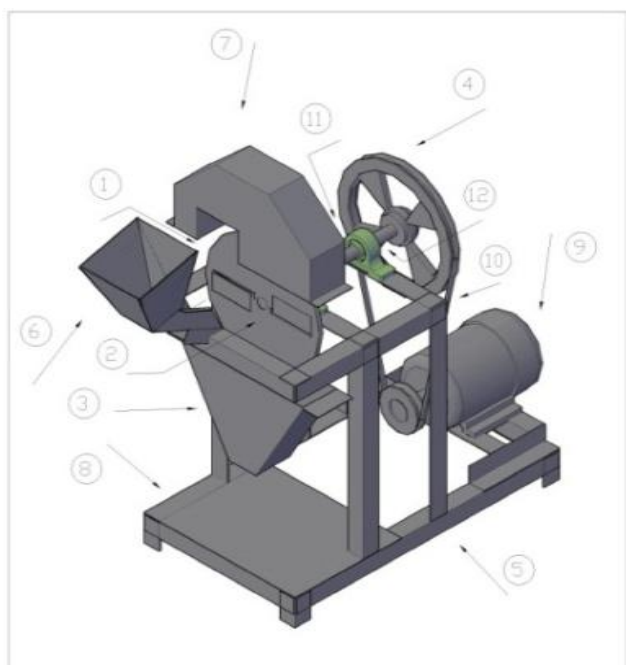

Gambar 2. Assembly Mesin Pengiris Bawang

\section{Keterangan :}

1) Dudukan Pisau

2) Pisau

3) Corong Bawah

4) Pully

5) Rangka

6) Corong Atas

7) Penutup Dudukan Pisau

8) Alas

9) Motor Listrik

10) V Belt

11)Bearing

12)Poros

Adapun komponen dari Alat pengiris bawang adalah sebagai berikut :

\section{1) Dudukan pisau}

Alat pengiris bawang yang saya buat menggunakan dudukan pisau sebagai tempat atau rumah pisau seperti pada Gambar 2 berikut ini :

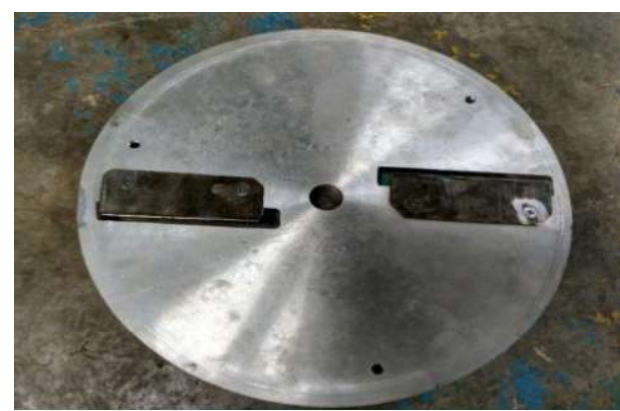

Gambar 2 Dudukan Pisau

Dudukan pisau ini berfungsi sebagai pengiris bawang yang akan diiris. Dudukan pisau ini terbuat dari alumunium yang telah dibuat dan dijual dipasaran sebagai dudukan pisau untuk mengiris. bawang, singkong dll. Dudukan pisau ini berdiameter dalam $22 \mathrm{~mm}$ dan diamter luar 315 mm dengan tebal $10 \mathrm{~mm}$. Dudukan pisau ini memiliki 2 mata pisau dengan ukuran panjang 100 $\mathrm{mm}$, lebar $40 \mathrm{~mm}$ dan tebal $2 \mathrm{~mm}$.

2) Pisau

Pisau adalah alat yang digunakan untuk memotong sebuah benda. Pisau terdiri dari dua bagian utama, yaitu bilah pisau dan gagang atau pemegang pisau. Bilah pisau terbuat dari logam pipih yang tepinya dibuat tajam; tepi yang takam ini disebut mata pisau. Pisau yang dipakai ialah pisau hasil buatan sendiri yang terbuat dari plat $2 \mathrm{~mm}$ dengan panjang $100 \mathrm{~mm}$ lebar $40 \mathrm{~mm}$, bisa dilihat pada Gambar 3 berikut ini :

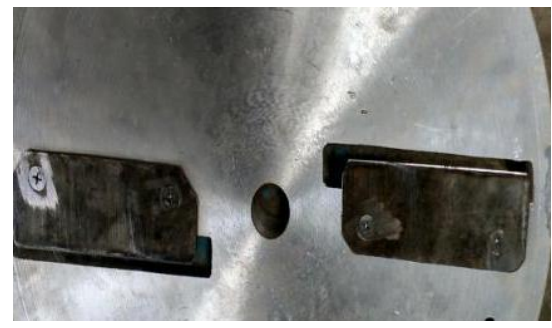

Gambar 3 Pisau

3) Corong Bawah

Corong bawah ini berfungsi untuk menampung hasil irisan agar tidak tercecer kemana - mana. Corong bawah ini terbuat dari plat alumunium dengan tebal plat $1 \mathrm{~mm}$ seperti terlihat pada Gambar 4.

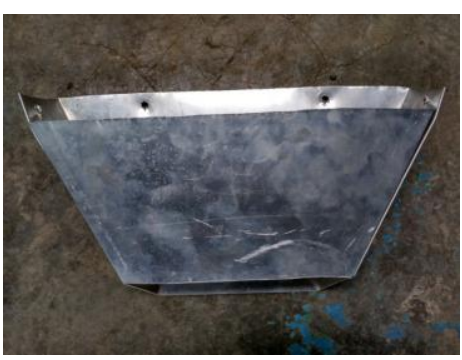

Gambar 4 Corong Bawah 


\section{4) Pully}

Pulley adalah suatu alat mekanis yang digunakan sebagai sabuk untuk menjalankan sesuatu kekuatan alur yang berfungsi menghantarkan daya. Pully yang digunakan adalah Type-A diameter 10 inchi sebanyak satu buah. Pully penerus dapat dilihat seperti pada Gambar 5 seperti berikut ini :

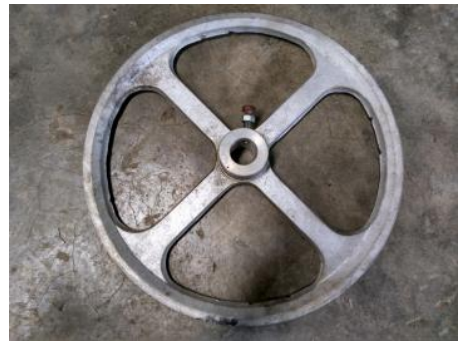

Gambar 5 Pully

5) Rangka

Rangka adalah bagian utama dari mesin pengaduk bumbu kerupuk ini, rangka merupakan penopang utama dari alat ini. Rangka dibuat dengan bahan besi profil L dengan ketebalan $4 \mathrm{~mm}$. Proses pengerjaan meliputi pemotongan besi, penggerindaan dan pengelasan. Rangka dapat dilihat seperti pada Gambar.6 berikut ini :

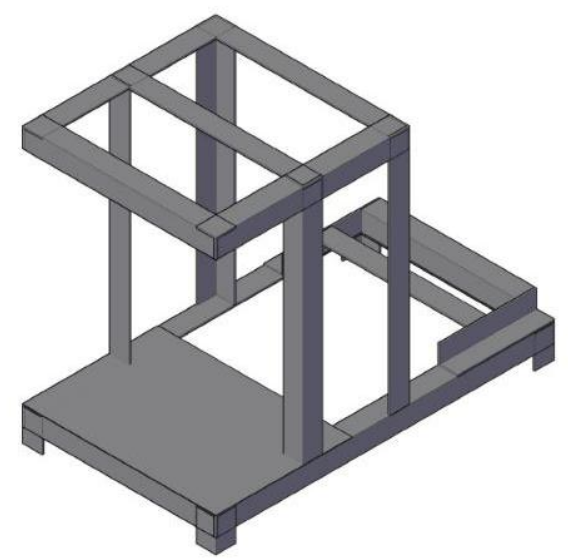

Gambar 6 Assembly Rangka

6) Corong Atas

Corong atas ini berfungsi untuk menampung bawang yang akan diiris. Corong atas ini terbuat dari plat alumunium dengan tebal $1 \mathrm{~mm}$. Ukuran corong atas ini ialah lebar $150 \mathrm{~mm}$ tinggi $100 \mathrm{~mm}$, dapat dilihat pada Gambar 4.7 berikut ini :

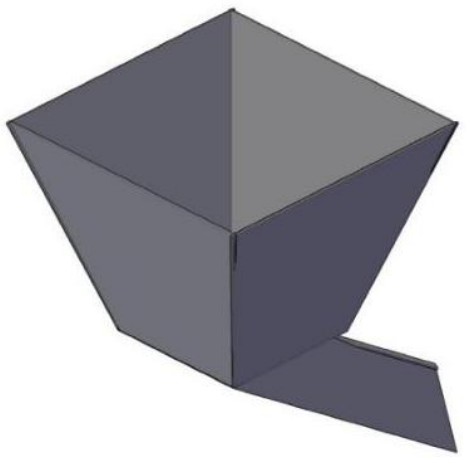

Gambar 4.7 Assembly Corong Atas

7) Penutup Dudukan Pisau

Penutup dudukan pisau ini berfungsi untuk menutup dudukan pisau dan sekaligus sebagi penahan agar hasil irisan tidak tercecer keluar. Penutup dudukan pisau ini terbuat dari plat stainless. Penutup dudukan pisau ini sengaja dibuat dari stainless agar menjaga kebersihan dari hasil irisan yang dihasilkan. Penutup dudukan pisau dapat dilihat pada Gambar 8 berikut ini :

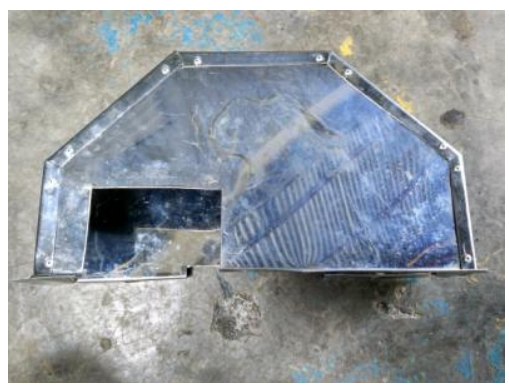

Gambar 8 Penutup Dudukan Pisau

8) Alas

Alas ini dibuat untuk menjadi landasan penampung bawang yang telah diiris. Alas ini terbuat dari plat dengan tebal $2 \mathrm{~mm}$ yang dilaskan langsung ke rangka. Ukuran alas ini ialah panjang $380 \mathrm{~mm}$ lebar $380 \mathrm{~mm}$.

9) Motor Listrik

Motor listrik adalah alat yang mengubah energi listrik menjadi energi mekanis. Motor listrik yang digunakan adalah daya $1 \mathrm{HP}$ dengan tegangan 220 V $50 \mathrm{~Hz}$ dan putaran $1400 \mathrm{Rpm}$. Motor yang digunakan pada alat pengiris bawang dapat dilihat pada Gambar 9. 


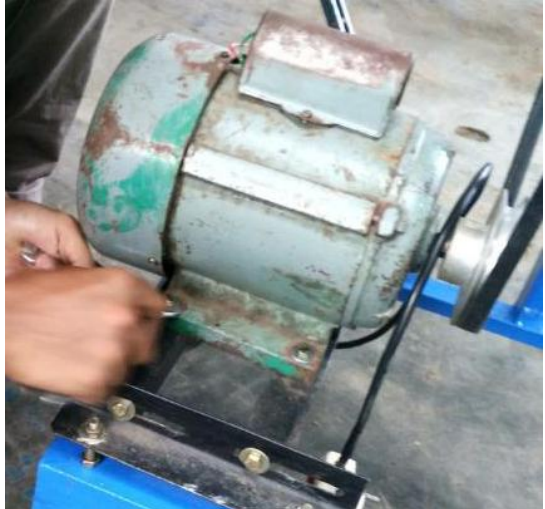

Gambar 9 Motor Listrik

\section{0) $V$ belt}

Sabuk/ V belt adalah sebuah produk tansmisi yang terbuat dari karet yang digunakan untuk mentransmisikan daya dari satu puli ke puli lainnya. Belt yang digunakan adalah Type-A 51 yang dapat dilihat pada Gambar 10.

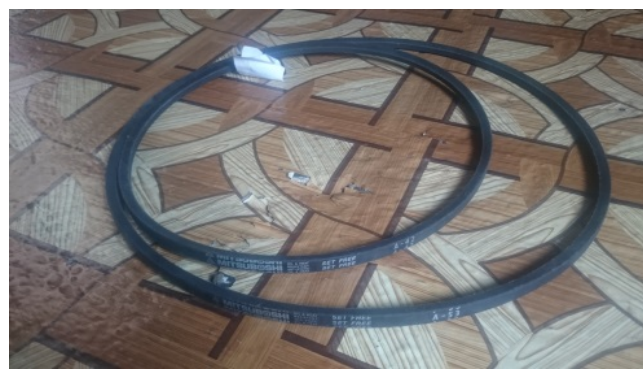

Gambar $10 \mathrm{~V}$ Belt

\section{1)Bearing}

Bearing dalam bahasa Indonesia berbarti bantalan. Dalam ilmu mekanika bearing adalah sebuah elemen mesin yang berfungsi untuk relatif antara dua atau lebih komponen mesin agar selalu bergerak pada arah yang diinginkan [5]. Bearing menjaga poros (shaft) agar selalu berputar terhadap sumbu porosnya, atau juga menjaga suatu komponen yang bergerak linier agar selalu berada pada jalurnya. Bearing yang digunakan adalah dengan merk GHB dengan no. P205 sebanyak 2 buah. Bearing yang digunakan dapat dilihat pada Gambar 11 berikut ini :

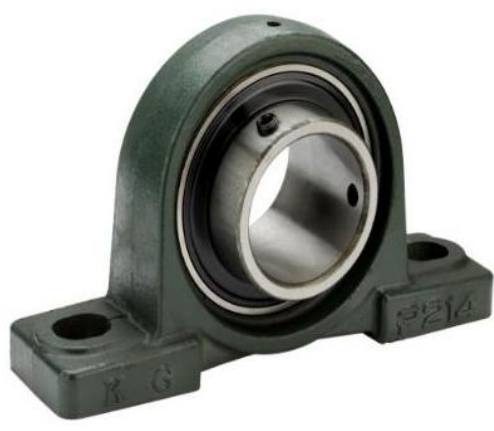

\section{Gambar 11 Bearing}

\section{Pembiayaan Pembuatan Mesin Pengiris Bawang}

Adapun penulis membahas tentang pembiayaan atau anggaran biaya dalam proses pembuatan mesin pengiris bawang ini. Pembiayaan atau anggaran dana pembuatan mesin pengiris bawang dapat dilihat pada Tabel 4.1.

Tabel 1 Anggaran Biaya Pembuatan Mesin Pengiris Bawang

\begin{tabular}{|c|c|c|c|}
\hline No & Barang & Biaya & Keterangan \\
\hline 1 & Besi Siku & Rp. 83.000 & Per 6 Meter \\
\hline 2 & Besi Pejal & Rp. 60.000 & Per batang \\
\hline 3 & Plat Stainless & Rp. 180.000 & Per lembar \\
\hline 4 & Plat alumunium & Rp. 138.000 & Per Lembar \\
\hline 5 & Plat tebal $2 \mathrm{~mm}$ & Rp. 38.000 & $\begin{array}{lllll}\text { Per } 1 & \text { meter } & x & 1 \\
\text { meter }\end{array}$ \\
\hline 6 & Pully & Rp. 100.000 & $1 \mathrm{Buah}$ \\
\hline 7 & Bearing & Rp. 45.000 & Per satuan \\
\hline 8 & Dudukan Pisau & Rp. 200.000 & $1 \mathrm{Buah}$ \\
\hline 9 & Elektroda & Rp. 30.000 & Per 50 Buah \\
\hline 10 & $V$ Belt & Rp. 29.000 & $1 \mathrm{Buah}$ \\
\hline 11 & Baut 8 & Rp. 2000 & Per 10 Buah \\
\hline 12 & Baut 10 & Rp. 2000 & Per 10 Buah \\
\hline 13 & Baut 12 & Rp. 2000 & Per 10 Buah \\
\hline 14 & Ring 8 & Rp. 2000 & Per 10 Buah \\
\hline 15 & Ring 10 & Rp. 2000 & Per 10 Buah \\
\hline 16 & Ring 12 & Rp. 2000 & Per 10 Buah \\
\hline 17 & Paku Rivet & Rp. 25.000 & Per 100 Buah \\
\hline 18 & Pasak & Rp. 5000 & $\begin{array}{llll}\text { Ukuran } & 5 & \mathrm{~mm} & \mathrm{x} \\
5 \mathrm{~mm} & & & \end{array}$ \\
\hline \multicolumn{2}{|c|}{ Total } & Rp. 947.000 & \\
\hline
\end{tabular}

*) total belum temasuk dengan biaya ongkos yang tidak terduga dan diluar dari motor karena motor listrik sebagai penggerak setatus pinjam.

\section{Pembuatan Mesin Pengiris Bawang}

Pembuatan konsep alat, berguna untuk memberikan beberapa solusi alternatif konsep produk, selanjutnya dievaluasi berdasarkan persyaratan teknis, ekonomis, dan lain-lain. Tahapan ini dapat diawali dengan mengenal dan menganalisis spesifikasi produk yang akan dibuat. Hasil analisis spesifikasi produk dilanjutkan dengan pembuatan desain gambar mesin yang akan dibuat, dapat dilihat pada Gambar 4.13 berikut:

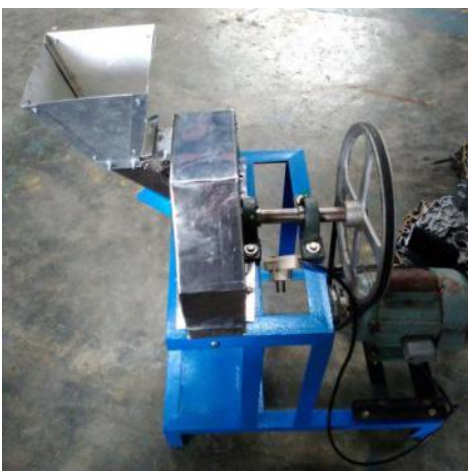


Gambar 12 Mesin Pengiris Bawang

Prinsip kerja mesin pengiris bawang ini adalah pada saat motor dihidupkan motor akan berputar sesusai dengan putaran motor, yang kemudian putaran pada motor tersebut ditransmisikan melalui pully dan sabuk $V$ belt dimana pully yang ada di motor akan meneruskan pada $v$ belt sehingga pully penerus yang ada pada bagian atas ikut berpotaran dengan arah putaran yang sama. Mesin pengiris bawang ini memiliki sitem transmisi yang terdiri dari 2 komponen yaitu pully dan $v$ belt. Mekanisme dari mesin pengiris bawang ini berawal dari motor listrik ditransmisikan ke pully motor lalu ditransmisikan menggunakan $v$ belt ke pully penerus yang ada pada bagian atas. Pada bagian pemotong mesin pengiris yang saya buat ini memiliki 2 mata pisau dengan dudukan berbahan besi alumunium yang telah tersedia langsung di pasaran. Pisau yang dipakai terbuat dari besi plat tebal $2 \mathrm{~mm}$ lalu di bentuk sesuai dengan dudukan mata pisau yang telah ada pada dudukan mata pisau. Untuk memudahkan proses pengirisan mesin pengiris bawang ini memili tadah penampung .

Adapun cara pembuatan komponen-komponen mesin pengiris bawang ini yaitu sebagai berikut:

\section{Rangka Mesin}

1) Alat
a) Mesin Las Listrik dan Perlengkapannya
b) Gerinda
c) Mesin Bor dan Perlengkapannya
d) Mata Bor 10 dan 12
e) Siku - siku, Mistar Baja dan Penitik
f) Mata Gerinda

2) Bahan

a) Besi Siku $40 \mathrm{~mm}$ x $40 \mathrm{~mm}$ x $4 \mathrm{~mm}$

b) Elektroda berdiameter 2,6

3) Langkah Kerja

a) Persiapkan alat dan bahan

b) Ukur besi siku sesuai dengan ukuran yang telah ditentukan, yaitu panjang $60 \mathrm{~cm}(2$ buah), $40 \mathrm{~cm}$ ( 5 buah), $7 \mathrm{~cm}$ (4 buah).

c) Potong besi siku sesuai dengan ukuran menggunakan gerinda potong duduk seperti dilihat pada Gambar 13

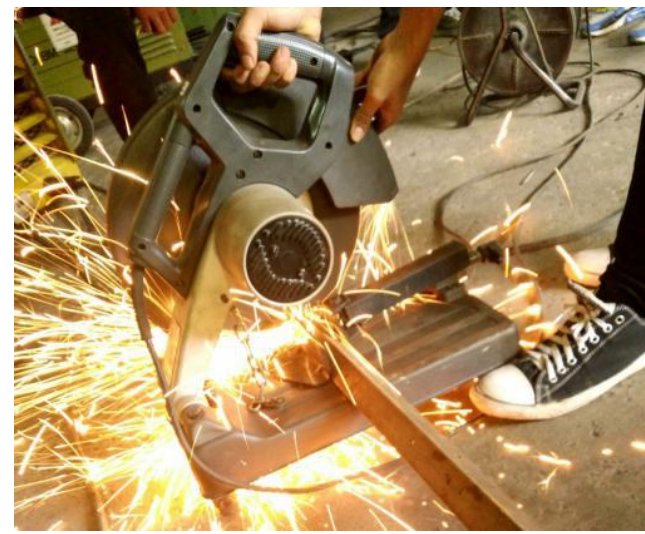

Gambar 13 Proses Pemotongan Besi Siku

d) Las besi siku panjang $60 \mathrm{~cm}$ dan $40 \mathrm{~cm}$ membentuk persegi

e) Sebelum lakukan pengelasan pastikan besi siku $60 \mathrm{~cm}$ dan besi siku 40 telah siku (900).

f) Setelah membentuk persegi lalu las besi siku panjang $50 \mathrm{~cm}$ tegak lurus dan las besi siku panjang $7 \mathrm{~cm}$ sebagai kaki pada rangka seperti dapat dilihat pada Gambar 4.15.

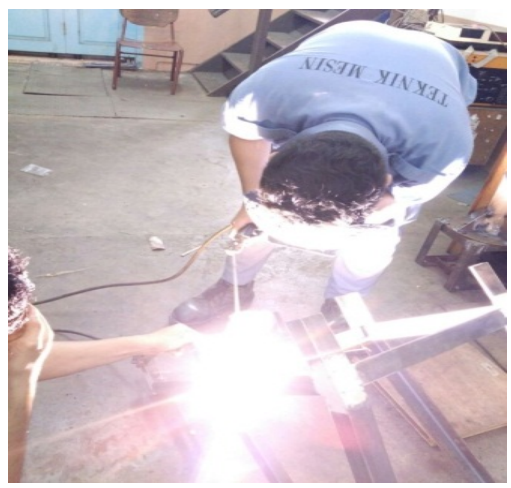

Gambar 14 Pengelasan Besi siku

Setelah selesai bagian itu maka lanjutkan pengerjaan dengan mengelas besi siku panjang $40 \mathrm{~cm}$ di bagian atas atau sebagai landasan untuk dudukan bantalan dan poros. Pengelasan selesai maka diteruskan dengan proses pengeboran untuk dudukan bearing (bantalan). Sebelum mengebor besi siku untuk dudukan bantalan maka terlebih dahulu melakukan pentikan pada pagian yang akan dilibangi menggunakan penitik dan palu sebagai pemukul. Lalu proses pengeboran menggunakan bor tangan seperti pada Gambar 15.

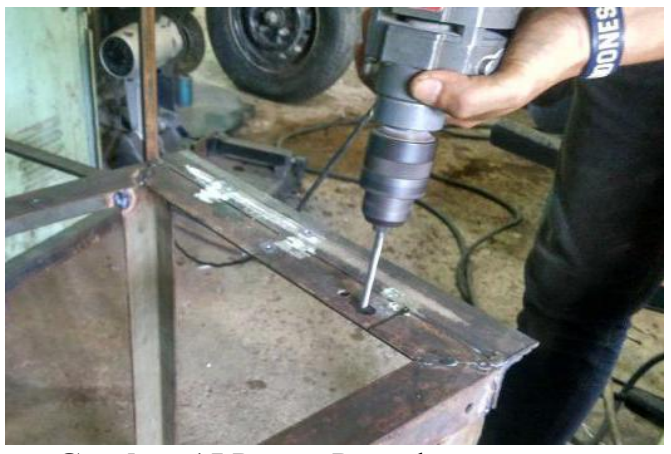

Gambar 15 Proses Pengeboran

Lalu gerinda rangka yang telah terbentuk untuk menghilangkan terak-terak yang menempel akibat proses pengelasan.

g) Selanjutnya teruskan dengan mengecet rangka agar rangka terlihat bagus. 


\section{Penutup Dudukan Pisau}

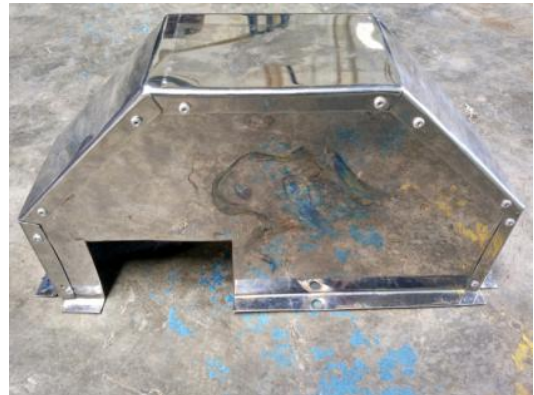

Gambar 16 Penutup Dudukan Pisau

Bor di pinggir plat yang telah dibentuk untuk lubang masuknya paku rivet. Gunting plat dibagian pinggir untuk lubang masuknya bawang ke dudukan pisau. Ukuran bolong pada penutup lebar $11 \mathrm{~cm}$ tinggi 7,5 $\mathrm{cm}$. Gabungkan plat yang telah terbentuk dengan bagian tengah dengan menggunakan paku rivet. Bagian penutup dudukan pisau selesai dibuat.

\section{Poros}

Adapun proses selanjutya ialah pembuatan poros, yaitu sebagai berikut :

a) Cekam bahan pada chack yang ada pada mesin bubut

b) Stel terlebih dahulu agar tidak baling bahan yang akan kita bubut

c) Lalu lakukan pemakanan dengan $1 \mathrm{~mm}$ dengan panjang $22 \mathrm{~mm}$ ke samping

d) Lalu makan kembali dengan pemakanan $1 \mathrm{~mm}$ sampai ukuran $22 \mathrm{~mm}$ dengan panjang $290 \mathrm{~mm}$

e) Proses pembuatan dapat dilihat pada Gambar 19 .

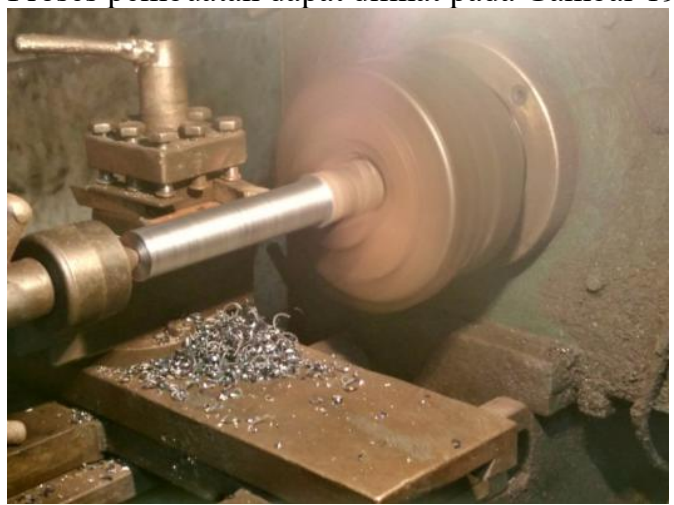

Gambar 19 Proses pembubutan poros

f) Setelah selesai maka lepas benda kerja dari pencekam dan lepas mata pisau bubut dari rumah mata pisau

g) Lalu bersihkan mesin bubut dan rapihkan alatalat yang telah dipakai

h) Proses pembuatan poros selesai.

\section{Perakitan Komponen-Komponen Alat}

Adapun langkah-langkah perakitan komponenkomponen mesin pengiris bawang ini addalah :

1) Pasang dudukan pisau ke poros yang telah dibubut. Poros yang dipakai berdiameter 25,2 mm. Seperti pada Gambar 20

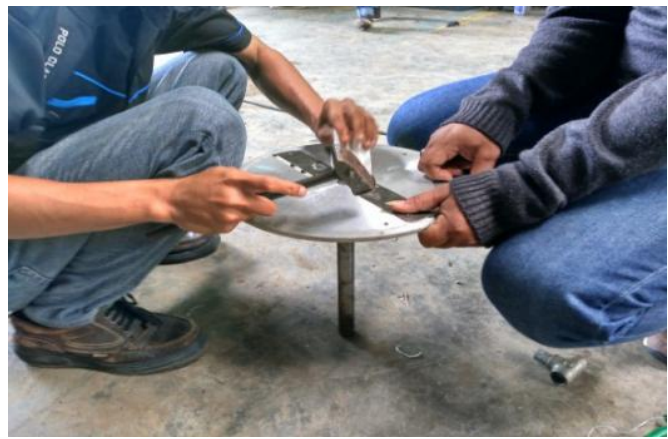

Gambar 20 Pemasangan dudukan pisau ke poros

2) Setelah terpasang maka tahap selanjutnya melakukan pemasangan bearing ke rangka dapat dilihat pada Gambar 21 dibawah ini :

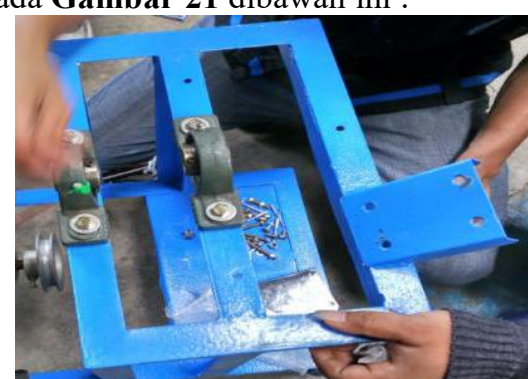

Gambar 21 Pemasangan Bearing pada rangka

3) Setelah bearing terpasang pada rangka lalu pasang poros yang telah terhubug dengan dudukan pisau

4) Pemasangan poros pada bearing dapat dilihat pada Gambar 22

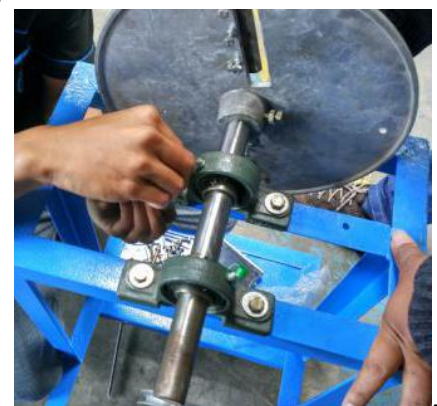

Gambar 22 Pemasangan Poros ke Bearing

5) Eratkan poros pada bearing dengan menggunakan kunci L

6) Lalu pasang pully 10 inch pada poros yang telah terpasang lalu eratkan dengan menggunakan kunci 12

7) Lalu pasang penutup dudukan pisau dan baut sebagai pengerat lalu kunci menggunakan kunci 12

8) Proses selanjutnya ialah melakukan pemasangan corong bawah ke rangka dengan menggunakan baut sebagai pengerat 
9) Selanjutnya pemasangan corong atas dengan menggunakan baut yang sama seperti pemasangan corong bawah

10) Bagian plat telah terpasang semua

11) Lalu selanjutnya pemasangan motor listrik pada rangka

12) Motor listrik disambung menggunakan baut 10 serta ring sebagai penyangga

13) Setelah motor terpasang maka proses selanjutnya pemasangan $V$ belt dari pully motor ke pully penerus

14) $V$ belt yang digunakan ialah tipe A-51

15) Setelah terpasang maka selanjutnya menyetel dudukan motor agar $V$ belt yang telah terpasang tegak lurus dari pully motor dengan pully penerus yang ada di atas. Dapat dilihat pada Gambar 23

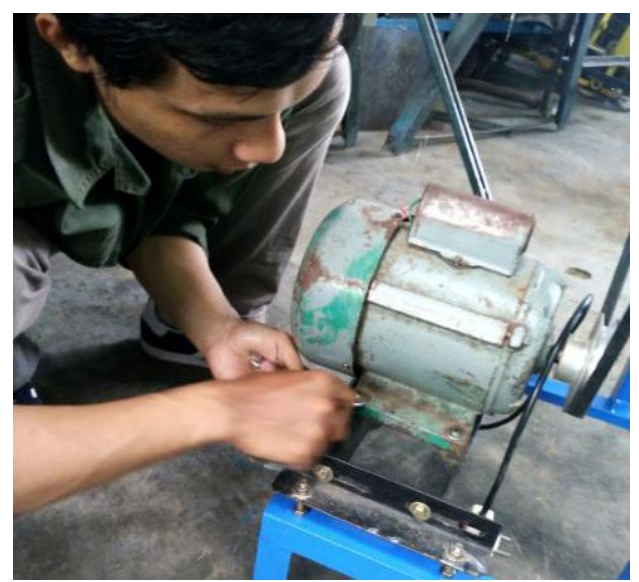

Gambar 23 Penyetelan dudukan motor
16) Maka proses perakitan selesai, alat siap di coba dan di oprasikan.

\section{Kesimpulan}

Adapun kesimpulan yang dapat penulis berikan pada proses pembuatan mesin pengiris bawang ini yaitu:

1) Komponen mesin pengiris bawang ini terdiri dari dudukan mata pisau, poros, bearing, pully, rangka mesin dan motor listrik.

2) Mengetahui anggaran biaya selama proses pembuatan mesin pengiris bawang dengan pasti. Mengetahui harga-harga komponen yang digunakan pada mesin pengiris bawang. Selama proses pembuatan diketahui total biaya yang dibutuhkan yaitu Rp. 947.000,00-

\section{Daftar Rujukan}

[1]. Koswara, S. 1992. Teknologi Pengelolahaan Makanan Bermutu. Jakarta: Pustaka Sinar Harapan

[2]. Widiantara, T., 2010. Rancang Bangun Alat Pengiris Bawang Merah dengan Pengiris Vertikal, Bandung

[3]. Rahmat, S., (2008), Optimasi Kapasitas Pengirisan yang Baik pada Bawang merah Besar Dengan Mesin Pengiris Bawang Merah Vertikal, Fakultas Teknik Universitas Diponogoro, Semarang

[4] Wiriaatmadja, Sutedja., (2002), Pengiris dan Pemotong, PT. Usaha Sistem Informasi Jaya (USI),Jakarta

[5] Suga, Kiyokatsu., Sularso (1997), Dasar Perancangan dan Pemilihan Elemen 